\title{
Avaliação Institucional: a busca pela integração dos resultados"
}

\author{
ADELINA DE OLIVEIRA NOVAES \\ Mestre e Doutoranda em Psicologia da Educação pela PUC-SP \\ adelina.novaes@fgv.br \\ LUCIANA BARBOSA MUSSE \\ Mestre e Doutora em Direito pela PUC-SP \\ luciana.musse@gmail.com
}

\begin{abstract}
Resumo
Este artigo apresenta a trajetória de criação e implementação de um novo processo avaliativo em um programa de pós-graduação lato sensu em Direito. Nesse contexto, as múltiplas variáveis relacionadas ao processo de ensino-aprendizagem foram consideradas na construção de nove instrumentos, que buscam também satisfazer os objetivos do projeto mais amplo de avaliação institucional. Com um desenho que procura a integração dos resultados, esta investigação tem como objetivo identificar demandas, ações positivas e dificuldades do processo ensino-aprendizagem. Os questionários, que contam com perguntas abertas e fechadas, são respondidos por professores, alunos, coordenadores e monitores do Programa. A sistematização, o processamento e a análise dos dados obtidos diariamente geram relatórios semanais, mensais, trimestrais e semestrais. Os resultados são continuamente enviados para os diferentes atores por e-mail. Os espaços de discussão desses resultados são variados, permitindo um processo contínuo. Com os dados obtidos até o momento, pode-se observar o aprimoramento da prática docente, porém percebe-se que uma reflexão mais qualificada só será possível com o avanço da investigação.

Palavras-chave: avaliação institucional, educação superior, lato sensu.
\end{abstract}

\section{Resumen}

Este artículo presenta la trayectoria de creación e implementación de un nuevo proceso evaluativo en un programa del posgrado lato sensu en derecho. En este contexto, las múltiples variables relacionadas al proceso de enseñanza-aprendizaje fueron consideradas en la construcción de nueve instrumentos, que buscan satisfacer también los objetivos de un proyecto más amplio de evaluación institucional. Con un diseño que busca la integración de los resultados, esta investigación tiene como objetivo identificar demandas, acciones positivas y dificultades del proceso de enseñanza-aprendizaje. Los cuestionarios, que cuentan con preguntas abiertas y cerradas, son respondidos por profesores, alumnos, coordinadores y monitores del Programa. La sistematización, el procesamiento y el análisis de los datos obtenidos diariamente generan informes semanales, mensuales, trimestrales y

* Artigo submetido à apreciação da Associação Brasileira de Avaliação Educacional - Abave. 
semestrales. Los resultados se envían permanentemente por e-mail a los diferentes actores. Los espacios de discusión de estos resultados son variados, permitiendo un proceso continuo. Los datos obtenidos hasta el momento, permiten observar mejoras en la práctica docente, sin embargo se percibe que una mayor calidad en la reflexión será posible sólo con el avance de la investigación.

Palabras clave: evaluación institucional, educación superior, lato sensu.

\begin{abstract}
This article presents the steps of the creation and implementation of a new evaluation process in a continuing education post graduation Law program. In this context, the multiple variables related to the teaching-learning process have been considered in the construction of nine new tools which aim at fulfilling the objectives of the broader project of institutional evaluation. Designed to integrate results, the objectives of this investigation are the identification of demands, positive actions and difficulties in the teaching-learning process. The questionnaires consist of subjective as well as objective questions, which are answered by teachers, students, coordinators, employees and the Program's assistants. The systematization, processing and analysis of the data obtained on a day-to-day basis generate weekly, monthly, quarterly and semesterly reports. The results are continuously sent to the different actors by e-mail. Room for debating these results varies, which makes for an ongoing process. With the data obtained up to now, teacher praxis improvements can be observed although more qualified reflection will only be possible with the advancement of the investigation.
\end{abstract}

Key words: institutional evaluation, higher education, continuing education. 
A mesma cadeira pode ser observada, enquanto objeto, por muitas pessoas. Suas características e propriedades materiais permanecem as mesmas, entretanto um decorador perceberá a cadeira de modo diferente de um marceneiro, de uma dona-decasa, de uma criança. Essas pessoas estabelecerão relações diferentes com o mesmo objeto. (Hoffman, 2003, p. 61)

\section{INTRODUÇÃO}

A educação superior brasileira é composta, grosso modo, de cursos e programas de graduação e pós-graduação lato e stricto sensu, que devem ser submetidos, periódica e sistematicamente, a um processo de avaliação para a aferição da sua qualidade.

A Lei n. 10.861, de 14 de abril de 2004, que instituiu o Sistema Nacional de Avaliação da Educação Superior (Sinaes), estabelece que a avaliação dos cursos de graduação e pós-graduação lato sensu deve ser efetuada pelo Inep, enquanto a avaliação dos programas de pós-graduação stricto sensu permanece sob a responsabilidade da Capes (Ristoff, Giolo, 2006, p. 199; Ribeiro, 2007).

Apesar de o Sinaes ser uma política de Estado instituída há mais de três anos, no âmbito dos cursos de graduação, a avaliação dos cursos de pós-graduação lato sensu ainda não foi implementada pelos órgãos governamentais responsáveis por sua execução (Conaes e Inep). Essa ausência de disciplinamento da avaliação institucional dos cursos de pósgraduação lato sensu - que, segundo Spagnolo e Sevilla (1994), Gomes (1999) e Pilati (2006), é histórica - não impediu, entretanto, que buscássemos desenvolver, no âmbito de um programa de especialização em Direito, uma proposta de auto-avaliação institucional integrada, nos moldes do que preconiza o Sinaes. Esta é a experiência que nos propomos a descrever no presente artigo.

\section{O PROGRAMA DE PÓS-GRADUAÇÃO E SUA DEMANDA}

Em um contexto de pós-graduação lato sensu em Direito, as múltiplas variáveis relacionadas ao processo de ensino-aprendizagem foram consideradas na construção de nove instrumentos avaliativos que compõem um processo integrado. 
Esta pesquisa tem como objetivo identificar demandas, ações positivas e dificuldades durante as atividades em sala de aula. Além disso, pretende-se que a avaliação do Programa participe de outra mais ampla: a avaliação da instituição de educação superior como um todo.

Apesar de os programas de pós-graduação lato sensu não sofrerem regulação específica quanto à auto-avaliação do próprio projeto e da sua atuação, recorremos às dez dimensões ${ }^{1}$ propostas pelo documento Diretrizes para a Avaliação das Instituições de Educação Superior do MEC/Inep/Conaes (Brasil, 2004), para a construção dos diferentes questionários que integram esse processo avaliativo.

Com base nessas dimensões, procuramos construir os instrumentos de maneira que possibilitassem: a avaliação de um objeto específico, a autoavaliação de cada respondente e a co-avaliação, ou seja, a avaliação dos pares. Inspiramo-nos no movimento denominado avaliação alternativa, dedicado à avaliação das aprendizagens:

Se trata de una evaluación formativa, compatible con la evaluación continua, que parte de la teoría del aprendizaje que considera que la ejecución es mejor cuando se conocen las metas, se conocen los critérios y los estándares que se tendrán en cuenta. A partir de aquí se promove la autoevaluación entre estudiantes y profesor (evaluación por portafolios) o entre ellos entre si (evaluación entre iguales). (Delgado García et al., 2006, p. 59)

Nosso intuito foi o de construir com os respondentes da pesquisa, compreendidos como atores da instituição e, conseqüentemente, da investigação, informações que permitissem uma avaliação formativa, consonante com a proposta do MEC/Inep/Conaes (Brasil, 2004).

Para tal, nos orientamos por uma perspectiva psicossociológica (Moscovici, 2003), pois compreendemos que há uma maneira coletiva de construção de representações que definem, para os integrantes de um grupo social, os objetivos e os procedimentos específicos que devem cumprir em sua vida diária, formando as referências que permitem aos sujeitos interpretar seu meio, dar sentido à realidade cotidiana.

1 As dez dimensões a serem consideradas na avaliação institucional: 1) missão institucional; 2) políticas de ensino, pesquisa, extensão da graduação e pós-graduação; 3) responsabilidade social da instituição; 4) comunicação com a sociedade; 5) políticas de pessoal, de carreiras do corpo docente, administrativo e técnico; 6) organização e gestão da instituição; 7) infra-estrutura física; 8) planejamento de avaliação; 9) políticas de atendimento ao estudante e egressos; 10) sustentabilidade financeira. 
Assim, considerar atores os professores, coordenadores, alunos, monitores e funcionários significa compreendê-los como agentes no processo de reflexão sobre suas representações e suas constituições como sujeitos coletivos no contexto institucional.

Para que esse processo avaliativo fosse possível, contamos com o principal agente de mediação entre a administração do Programa e a sala de aula: o monitor ${ }^{2}$. Com seu auxílio, buscou-se compreender a percepção de alunos, professores e coordenadores dos cursos de educação continuada e especialização a respeito de suas próprias ações, as ações dos demais agentes da instituição e sobre o Programa, no que diz respeito à gestão, infra-estrutura, atendimento etc. Para tal, o monitor responsabilizou-se por: 1) sensibilizar os demais atores acerca da importância da avaliação; 2) receber, na secretaria, os questionários; 3) coletar os dados; 4) conferir os questionários respondidos; 5) devolver os instrumentos à secretaria.

\section{A AVALIAÇÃO INSTITUCIONAL}

Para realizar a auto-avaliação institucional, Sousa (2006) propõe o agrupamento das dez dimensões indicadas pelo MEC/Inep/Conaes, em quatro grandes grupos:

- Missão;

- Instituição e Sociedade;

- Gestão e Apoio;

- Políticas.

Esses focos avaliativos devem ser pensados de maneira integrada, pois participam de uma área investigativa comum. Por isso, é necessário analisá-los com um olhar atento, orientado pela missão da instituição.

A autora ilustra sua proposta de reorganização das dez dimensões avaliativas da seguinte maneira:

2 O monitor é estudante de graduação, pós-graduação, ou, ainda, um profissional que tem interesse pelo conteúdo ministrado no módulo, ou afinidade com ele; possui atribuições administrativas e pedagógicas. 


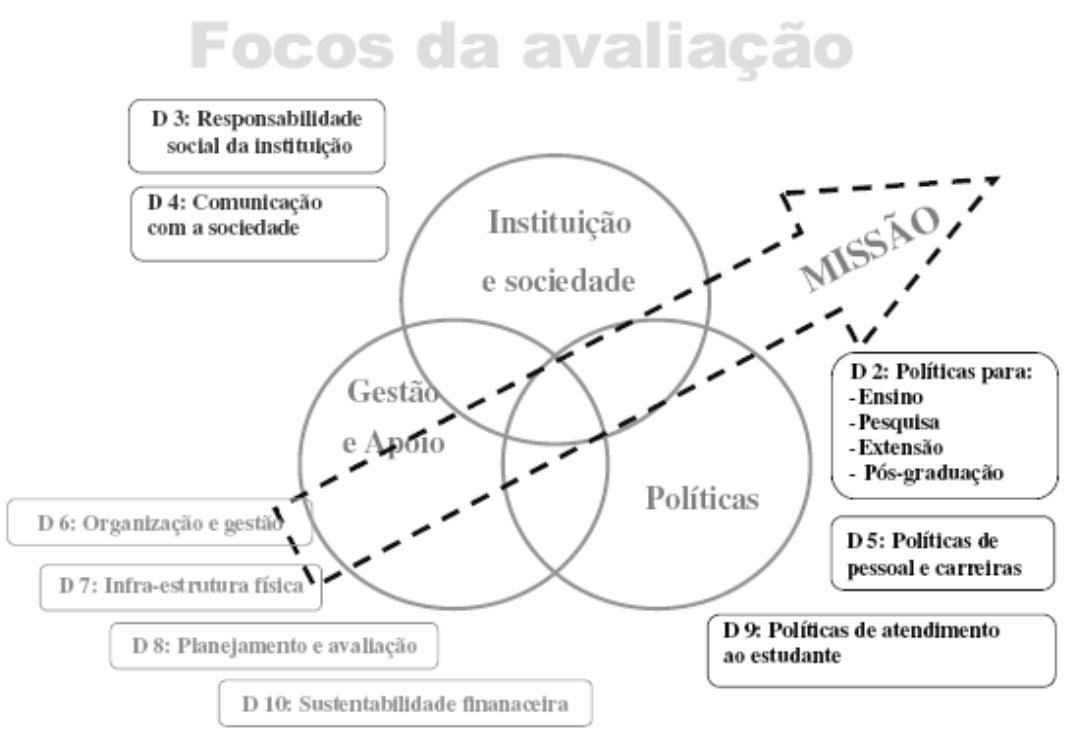

Seguindo a orientação de Sousa (2006), o projeto de auto-avaliação da instituição se organizou em quatro ciclos avaliativos:

1. A missão vivida na instituição e sua relação com o Projeto de Desenvolvimento Institucional, iniciado em 2005 e concluído em março de 2006.

2. A instituição e sua relação com a sociedade, iniciado em 2006, em fase de conclusão.

3. A gestão e o apoio da instituição, cujo início estava previsto para o fim de 2007.

4. As políticas de ensino, pesquisa, extensão, de atendimento ao estudante, de pessoal e de carreira, com início previsto em 2008.

Cada ciclo, com duração aproximada de um ano, focaliza seu olhar em uma temática específica, sem deixar de fazer o levantamento das outras dimensões avaliativas.

Dessa maneira, o primeiro ciclo de auto-avaliação teve como foco a missão e o Projeto de Desenvolvimento Institucional (PDI) e pretendeu explicitar as finalidades, os objetivos e os compromissos que a instituição assume. Como questão avaliativa, trabalhou-se com os coordenadores, professores, pesquisadores, alunos e funcionários a missão declarada da instituição no PDI e a missão vivida na instituição. 
Após o estudo do PDI, a Comissão Própria de Avaliação (CPA) construiu instrumentos que permitiram a análise entre o declarado e o vivido. Os questionários respondidos pelos atores da instituição, na graduação e na especialização, foram analisados e ressignificados pelos próprios atores por meio de grupos focais (Morgan, 1997), encontros com as coordenações e plenárias.

Os grupos focais foram trabalhados como foros facilitadores da expressão de características psicossociológicas, ou seja, buscou-se nessas discussões compreender as percepções, crenças, valores, atitudes $e$ representações sociais (Westphal, Bógus, Faria, 1996, p. 473) de professores e funcionários a respeito de suas próprias atuações, das atuações dos demais colegas da instituição e sobre o Programa, de maneira global.

Nos encontros com as coordenações e nas plenárias institucionais, o objetivo era um pouco distinto. $\mathrm{O}$ interesse também era o de permitir a reflexão sobre o processo, mas de maneira menos planejada e sem gerar um dado direto para a investigação avaliativa; lá o principal interesse era o da análise mais aprofundada dos dados.

A devolução dos dados do primeiro ciclo permitiu uma maior discussão acerca da importância dos processos avaliativos na instituição. A revisão e atualização do PDI e do regimento da CPA também foram consideradas necessárias. E essas ações estão sendo desenvolvidas atualmente. A divulgação e discussão dos resultados também permitiram maior envolvimento dos atores com o Projeto e, nesse contexto, a instituição pode definir o novo foco avaliativo, dando prosseguimento ao planejamento realizado no início deste processo.

\section{A PESQUISA AVALIATIVA NO PROGRAMA}

A cultura avaliativa do Programa de Pós-Graduação da Instituição tem como foco a qualidade da educação que é dada aos seus alunos e o seu impacto no mundo do trabalho, que recebe os profissionais que são ali formados.

Dessa forma, o processo avaliativo busca oferecer subsídios aos gestores do Programa para analisar, continuamente, a qualidade do bem 
público que é construído: a educação ${ }^{3}$. Por isso, desde o início do seu funcionamento, em 2000, o Programa já havia desenvolvido instrumentos de avaliação do rendimento docente, simultaneamente à auto-avaliação discente e à avaliação do rendimento do aluno, feita pelo professor. $\mathrm{O}$ novo processo avaliativo teve como desafio ampliar a participação dos atores do processo de ensino-aprendizagem, até então restrita aos alunos, monitores e professores, trazendo a avaliação para o cotidiano também dos coordenadores e do pessoal de apoio do Programa.

Sendo um programa de pós-graduação lato sensu que conta com muitos alunos (aproximadamente 1.200), professores (200 por semestre, em média), coordenadores (cerca de 50), monitores (cerca de 40) e funcionários (aproximadamente 20), temos em andamento nove cursos de especialização e seis cursos de educação continuada, nos quais foram coletados os dados que embasaram algumas das reflexões e ações apresentadas neste artigo.

Nesse cenário, a modificação das práticas avaliativas exigiu um trabalho intenso de sensibilização de toda a comunidade acadêmica alunos, monitores e professores - porque houve uma mudança significativa nos instrumentos e na periodicidade da avaliação.

No modelo antigo, os alunos avaliavam o professor, o curso e sua infra-estrutura em um único instrumento. Em função do grande número de professores que ministravam uma única aula em cada módulo, a coleta dos dados era realizada nesse encontro do professor com a turma. Se o professor, por exemplo, tivesse mais de uma aula no módulo, a coleta era feita na última aula. A utilização desse critério - número de aulas ministradas pelo professor - para se fixar a periodicidade da coleta dos dados foi alterada no novo processo avaliativo, conforme descreveremos adiante.

O questionário respondido pelo monitor também sofreu alterações. No intuito de dar conta dos aspectos pedagógicos, incluiu-se, além das questões administrativas - entrega de material no prazo, assiduidade e pontualidade do professor -, questões sobre métodos de ensino e material didático.

3 Essa preocupação institucional é consonante com a concepção de educação adotada pelo Sinaes. "Não por acaso, portanto, o Sinaes usa a palavra educação e não ensino para identificar-se. Seus elaboradores entendem que educação expressa um conceito mais amplo que ensino, transcendendo o desempenho e o rendimento de estudantes, aferidos por meio de provas de larga escala, devendo buscar os significados mais amplos da formação e colocando como questão central a responsabilidade social das IES com o seu entorno, com a formação de cidadãos altamente qualificados e com o avanço da arte e da ciência" (Ristoff, Giolo, 2006, p. 205, grifo nosso). 
A sensibilização dos coordenadores acadêmicos e gestores fez-se necessária em virtude do seu ingresso em um universo no qual, até então, participavam apenas como espectadores ou como aqueles que eram avaliados pelos alunos e monitores dos seus respectivos cursos. A participação dos membros do corpo técnico-administrativo apresenta-se como outro elemento distintivo do novo processo avaliativo do Programa. Eles passaram a integrar o grupo dos respondentes no projeto mais amplo de auto-avaliação institucional e, também, a terem seus desempenhos avaliados por alunos, professores e coordenadores acadêmicos.

Por isso, o envolvimento da comunidade acadêmica no processo avaliativo foi e continua sendo estimulado por intermédio de uma multiplicidade de meios de comunicação: reuniões, mensagens eletrônicas, capacitação de agentes multiplicadores, entrevistas, cartões e cartazes afixados nas salas de aula.

\section{A TRAJETÓRIA METODOLÓGICA}

Tendo por objetivo compreender as diferentes relações dos atores da pós-graduação com o Programa e com o processo de ensinoaprendizagem, foram construídos instrumentos que dessem conta das relações ilustradas a seguir.

\section{Gráfico 1 - Avaliação do Aluno}

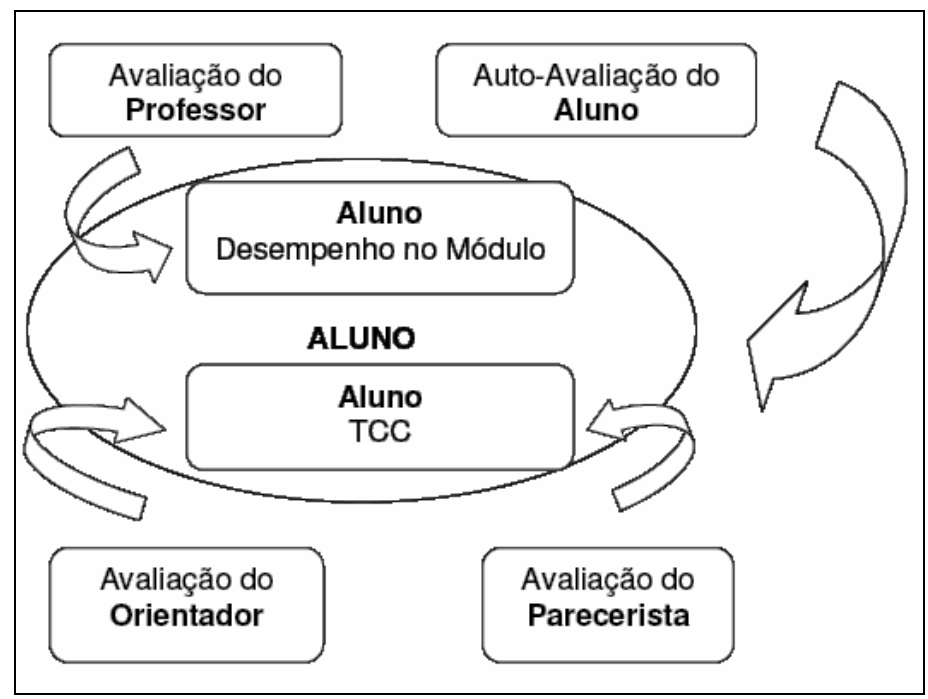

Estudos em Avaliação Educacional, v. 19, n. 39, jan./abr. 2008 
Apesar da sensibilização que se tem feito com os coordenadores para que desenvolvam uma avaliação contínua do desempenho dos alunos nos módulos, a maioria ainda o faz utilizando apenas critérios somativos. $\mathrm{O}$ Programa estabelece que o desempenho deverá ser avaliado por intermédio de uma prova que representa, no máximo, $70 \%$ da nota total. Os 30\% restantes podem ser destinados à avaliação de trabalhos e à sua participação no módulo.

Verifica-se que a auto-avaliação do aluno reflete a avaliação que ele faz do professor, ou seja, se o aluno avalia negativamente o professor atribui também a si um mau desempenho no módulo.

A avaliação do TCC é feita pelo orientador e pelo parecerista, levando em conta a matriz avaliativa construída coletivamente nas reuniões de metodologia do ensino com os professores da escola. Tanto o orientador como o parecerista devem verificar se o aluno possui domínio da forma, do conteúdo e dos métodos de pesquisa. O TCC é apresentado pelo aluno após o término do último semestre letivo cursado.

\section{Gráfico 2 - Avaliação do Professor}

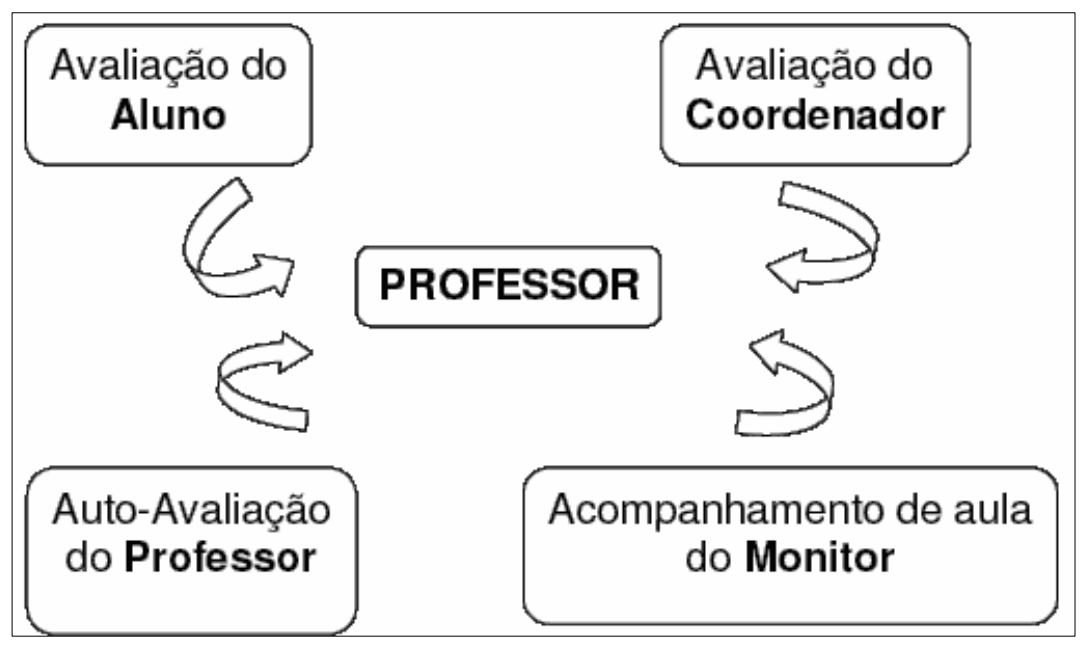

No processo avaliativo anterior, o professor era avaliado apenas pelo aluno e pelo monitor, no dia da aula, se fosse um único encontro, ou na última aula, caso atribuíssem ao professor duas ou mais aulas.

Nessa nova proposta, a auto-avaliação e a avaliação do coordenador acadêmico foram introduzidas a fim de possibilitar, com o confronto dos 
dados fornecidos pelos quatro diferentes atores, maior fidedignidade da situação vivenciada em sala de aula.

Destacamos que tanto os monitores como os coordenadores de curso devem acompanhar o desenvolvimento do módulo, assistindo às aulas ministradas e respondendo aos questionários a cada encontro, para que os ajustes sejam feitos, se necessários, no menor tempo possível e com o menor impacto sobre a vida acadêmica do aluno.

O professor se auto-avalia num único momento do módulo, mesmo que seja responsável por mais de uma aula.

Os alunos avaliam o professor uma vez, caso o professor tenha até três aulas no módulo. Se o professor for responsável, num módulo, por quatro aulas ou mais, será avaliado em dois momentos distintos.

Entre os principais pontos a serem avaliados pelos alunos, coordenadores, monitores e pelo próprio professor, encontram-se o método de ensino e o material didático utilizados por ele. Tal ênfase deve-se, primeiramente, ao fato de os cursos tradicionais de graduação e pósgraduação em Direito privilegiarem as aulas expositivas e manuais. O principal motivo, contudo, é que a utilização de novos métodos de ensino em Direito apresenta-se como um dos diferenciais a serem oferecidos pela Escola de Direito de São Paulo, da Fundação Getúlio Vargas.

\section{Gráfico 3 - Avaliação do Coordenador}

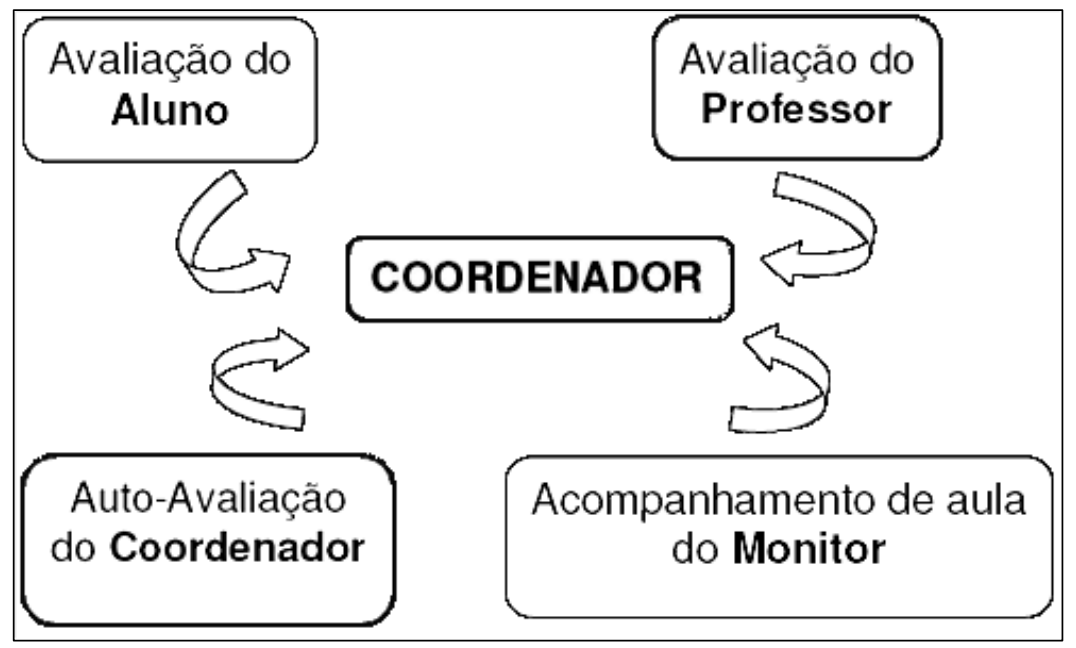


Os dados para a avaliação do coordenador, pelo aluno, bem como sua auto-avaliação, são coletados ao final do módulo. Vale ressaltar que a auto-avaliação do coordenador foi introduzida neste novo processo avaliativo. A avaliação do coordenador, feita pelo monitor do módulo, é realizada em todos os encontros. Essa modalidade de avaliação do coordenador também foi introduzida pela nova proposta do processo avaliativo. Já a avaliação do coordenador, feita pelos professores do módulo, é realizada no dia em que cada docente ministrar sua aula no módulo.

\section{Gráfico 4 - Avaliação do Programa}

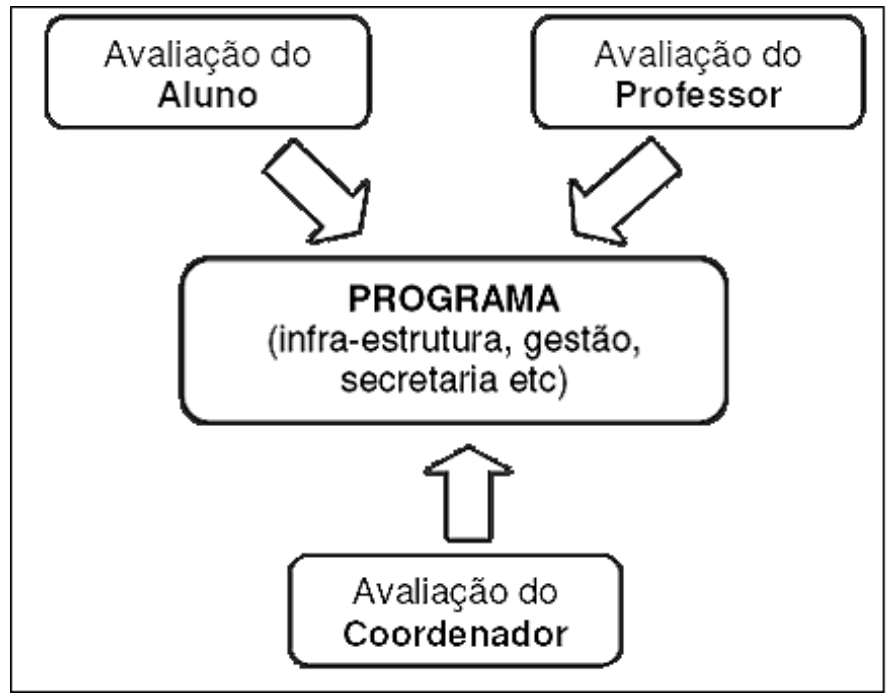

A avaliação do Programa, feita pelos alunos, pelos professores e pelos coordenadores, ocorre em dois momentos distintos: na metade e ao final do módulo, a fim de que se possa comparar os resultados e verificar se houve alteração, para melhor ou para pior, dos aspectos apontados pela(s) turma(s). 
O processo avaliativo do Programa conta com nove instrumentos de avaliação, a saber:

- acompanhamento da aula pelo(a) monitor(a);

- acompanhamento da aula pelo(a) coordenador(a);

- questionário sobre o Módulo;

- questionário sobre o Programa;

- questionário de Auto-Avaliação do(a) Coordenador(a);

- questionário de Auto-Avaliação do(a) Professor(a);

- questionário de Avaliação do Módulo de Seminário de Pesquisa;

- questionário de Auto-Avaliação do(a) Orientador(a);

- matriz de Avaliação do Trabalho de Conclusão do Curso (TCC).

A coleta é realizada pelos monitores dos módulos que foram capacitados pela equipe de avaliação para a realização dessa atividade.

Além do levantamento de dados por meio de questionários, a pessoa responsável pelas questões de avaliação e metodologia de ensino realiza a observação in loco das aulas ministradas nos módulos do Programa. Denominada Observatório Metodológico, essa estratégia tem por objetivo mapear as diferentes experiências de ensino, utilizando metodologias participativas. Tal iniciativa tem a finalidade, ainda, de verificar eventuais melhorias no desempenho de professores que participaram de cursos de formação docente oferecidos pelo Programa, com base na análise e interpretação dos dados coletados por intermédio do processo avaliativo.

A sistematização, o processamento e a análise dos dados obtidos diariamente geram relatórios semanais, mensais, trimestrais e semestrais. A síntese dos instrumentos, os respondentes e a periodicidade dos relatórios parciais são mostrados no Quadro 1. 
Quadro 1 - Instrumentos, respondentes e periodicidade dos relatórios

\begin{tabular}{|l|c|c|}
\hline \multicolumn{1}{|c|}{ Instrumento } & Respondentes & $\begin{array}{c}\text { Periodicidade } \\
\text { dos Relatórios }\end{array}$ \\
\hline Questionário sobre o Módulo & Aluno & Semanal \\
\hline Questionário sobre o Programa & $\begin{array}{c}\text { Aluno } \\
\text { Professor } \\
\text { Coordenador }\end{array}$ & Trimestral \\
\hline $\begin{array}{l}\text { Questionário de Auto-Avaliação do } \\
\text { Professor }\end{array}$ & Professor & Trimestral \\
\hline $\begin{array}{l}\text { Questionário de Auto-Avaliação do } \\
\text { Coordenador }\end{array}$ & Coordenador & Trimestral \\
\hline Acompanhamento da Aula pelo Monitor & Monitor & Semanal \\
\hline $\begin{array}{l}\text { Acompanhamento da Aula pelo } \\
\text { Coordenador }\end{array}$ & Coordenador & Semanal \\
\hline Matriz de Avaliação do TCC & $\begin{array}{c}\text { Orientador/ } \\
\text { Avaliador de TCC }\end{array}$ & Semestral \\
\hline $\begin{array}{l}\text { Questionário de Auto-Avaliação do } \\
\text { Orientador de TCC }\end{array}$ & Orientador de TCC & Semestral \\
\hline $\begin{array}{l}\text { Questionário sobre o Módulo de } \\
\text { Seminário de Pesquisa }\end{array}$ & $\begin{array}{c}\text { Aluno em } \\
\text { Orientação de TCC }\end{array}$ & Trimestral \\
\hline
\end{tabular}

Dessa forma, buscou-se, por meio de questionários, que contam com perguntas abertas e fechadas, a avaliação dos atores do processo ensino-aprendizagem e do Programa como um todo, bem como a autoavaliação de cada ator e a co-avaliação entre pares.

Os resultados têm-se mostrado pertinentes para reflexões futuras mais aprofundadas com os atores, uma vez que o porcentual de respostas tem sido, entre os alunos, de cerca de $80 \%$, graças à sensibilização feita pelos monitores, e acima de $90 \%$ para os questionários respondidos por monitores, professores e coordenadores. Com base na análise dos dados dos próprios atores do Programa, pretende-se construir novas informações que alimentarão a investigação do projeto avaliativo mais amplo, o da avaliação institucional. $\mathrm{O}$ processo de devolução dos resultados tem sido contínuo. As informações acerca da avaliação são enviadas por e-mail, e os resultados vêm sendo discutidos e trabalhados com os respondentes em diferentes espaços e momentos. 
O professor recebe uma síntese da sua avaliação, uma compilação dos resultados obtidos pela avaliação feita pelos alunos, pelos coordenadores, pelo monitor e por ele mesmo. As categorias que pretendem dar conta do desempenho do professor em sala ${ }^{4}$ são trabalhadas em uma gradação que vai do insuficiente ao excelente. Essa gradação aplica-se a todas as categorias, em todos os questionários. Seguindo a mesma lógica de estruturação dos relatórios, além da coordenação acadêmica do curso ser avaliada ${ }^{5}$, recebe a síntese da avaliação sobre sua atividade como coordenador, da avaliação a respeito dos professores, um relatório detalhado da avaliação do módulo e os resultados de sua própria auto-avaliação.

Os alunos recebem os resultados da avaliação do seu desempenho nos módulos e no Trabalho de Conclusão de Curso (caso estejam em processo de orientação, ou já tenham concluído o TCC), bem como a sua auto-avaliação ${ }^{6}$ e os resultados da avaliação do Programa.

Os setores acadêmico-administrativos do Programa também são avaliados $^{7}$ e informados sobre os resultados das avaliações de sua área nas reuniões semanais da equipe.

Vale salientar que o Programa não fica de fora, sendo avaliado nos aspectos curriculares e didáticos, por exemplo, quanto ao número de módulos oferecidos por semestre, carga horária, coerência entre eles, adequação dos conteúdos dos módulos às propostas do curso, relevância dos conteúdos trabalhados para sua prática profissional, bem como nos aspectos de infra-estrutura: instalações, recursos audiovisuais disponíveis, horário de funcionamento do laboratório de informática e biblioteca, acervo

4 A saber: clareza na exposição dos conteúdos, distribuição das atividades no tempo, metodologia de ensino, material didático, domínio do conteúdo pelo professor, ampliação do nível de conhecimento do aluno, entre outras previstas no questionário e aquelas indicadas pelos respondentes em um espaço de Comentários e Sugestões.

5 A coordenação do curso, entre outros aspectos, é avaliada no que diz respeito ao planejamento acadêmico do módulo, programação das aulas, comunicação com professores, monitores, alunos e com a equipe administrativa do Programa, e resolução das demandas acadêmicas por parte dos docentes.

6 Os alunos se avaliam quanto a preparação para a aula (leituras, pesquisa extraclasse), pontualidade, atenção à aula, respeito aos colegas, participação na aula e rendimento alcançado.

7 Os setores técnico-administrativos são avaliados levando-se em consideração o processo de matrícula e rematrícula, a comunicação com alunos, professores, coordenadores e demais funcionários, quanto às informações prestadas sobre procedimentos e expedição de documentação, entrega de material didático, e resolução das demandas administrativas de alunos, professores, coordenadores e colegas. 
da biblioteca, número de alunos por turma etc. Aspectos que serão analisados no âmbito do projeto mais amplo de auto-avaliação institucional.

\section{PROPOSTA DE ANÁLISE COLETIVA DOS RESULTADOS}

As questões específicas de sala de aula e orientação são enfrentadas em dois espaços de discussão. Mesmo tendo desenhos distintos, esses espaços compartilham os seguintes objetivos: discutir os resultados, identificar as ações positivas e buscar meios de atender às demandas identificadas nas avaliações dos alunos, professores e coordenadores.

O primeiro desses espaços de discussão denomina-se Café Metodológico. Os encontros são mensais e têm duração de duas horas. Deles participam convidados - profissionais da área da educação - para debaterem com o grupo de professores, coordenadores e monitores as temáticas suscitadas por eles. A ênfase está no desenvolvimento de uma reflexão teórico-crítica acerca das especificidades do processo ensinoaprendizagem na educação em nível de especialização.

A prática docente é central no segundo espaço de discussão, intitulado Sala de Aula em Foco, onde acontecem, quinzenalmente, oficinas pedagógicas em que os professores desenvolvem atividades eminentemente práticas.

O Seminário Semestral caracteriza-se por ser um espaço de balanço das atividades acadêmicas desenvolvidas em um semestre e de preparação para o semestre letivo subseqüente. Nele é analisada a trajetória do Programa realizada pelos gestores, coordenadores e professores dos cursos. Pode-se afirmar que a conclusão parcial do processo de avaliação do Programa ocorre nesse evento.

As discussões sobre as avaliações dos alunos têm sido feitas na própria sala de aula, pois não há disponibilidade para encontros em outros momentos que não aqueles destinados às aulas. Há também discussões efetuadas regularmente pelos técnico-administrativos, após o recebimento dos resultados das avaliações de seus setores.

\section{CONSIDERAÇÕES FINAIS}

O processo avaliativo de uma instituição deve envolver a análise da atuação acadêmica e administrativa dos diferentes atores, estejam eles na 
graduação, na pós-graduação stricto sensu, e também nos programas de educação continuada e de especialização.

A primeira análise dos resultados do esforço de integração da avaliação institucional com a avaliação específica do Programa de Pósgraduação lato sensu mostra-se positiva, pois pôde-se perceber o aprimoramento da prática docente, por meio das análises realizadas no Projeto Observatório Metodológico, principalmente após o início dos encontros Café Metodológico e Sala de Aula em Foco. Infelizmente, o número de docentes participantes desses encontros ainda é muito reduzido, se levarmos em conta o total por semestre, não chegando a representar um terço do grupo.

Assim, consideramos que a sensibilização, além de contínua, deve sempre recorrer a mídias variadas, para que os coordenadores e os docentes participem dos encontros de formação e de reflexão sobre sua prática. Em virtude das reuniões realizadas com os funcionários, em seus setores específicos, eles perceberam a necessidade de ampliação da equipe administrativa e de sua capacitação por meio de cursos de educação continuada e de especialização. O diagnóstico levantado nos diferentes instrumentos avaliativos também mudou sua forma de atuar. Após refletirem sobre os dados, eles têm organizado melhor as rotinas e feito reuniões mais freqüentes para discutir aspectos de seu cotidiano profissional.

Acredita-se que espaços mais específicos para a discussão das avaliações com os alunos devam ser pensados, pois já evidenciaram a dificuldade que têm para participar de encontros fora do horário destinado às aulas.

Esta trajetória avaliativa acaba de começar e, apesar de os dados indicarem um avanço, fica claro para nós que a consolidação da cultura avaliativa ainda está em desenvolvimento e requer um ajustamento, e que uma reflexão mais qualificada do processo de ensino-aprendizagem só será possível com o progresso dessa investigação.

\section{REFERÊNCIAS BIBLIOGRÁFICAS}

BRASIL. Ministério da Educação. Diretrizes para a Avaliação das Instituições de Educação Superior. Brasília: Instituto Nacional de Estudos e Pesquisas Educacionais Anísio Teixeira; Coordenação Nacional de Avaliação do Ensino Superior, 2004. 
BRASIL. Lei n. 10.861, de 14 de abril de 2004. Institui o Sistema Nacional de Avaliação da Educação Superior - Sinaes e dá outras providências. DOU, Brasília, n. 72, 15 abr. 2004. Seção 1, p. 3. Disponível em: <http://www.presidencia.gov.br/legislacao/>. Acesso em: 10 jul. 2007.

DELGADO GARCÍA, A. M. et al. Evaluación de las competencias en el espacio europeo de educación superior: un experiencia desde el Derecho y la Ciencia Política. Barcelona: Bosch, 2006.

FRAUCHES, C. da C. Pós-graduação lato sensu tem novas normas: Resolução CES/CNE n. 1/2007. Disponível em: <www.abmes.org. br>. Acesso em: 15 out. 2007.

FUNDAÇÃO GETÚLIO VARGAS. Escola de Direito de São Paulo. Projeto de Desenvolvimento Institucional (PDI). São Paulo: FGV, 2004.

GOMES, Cândido Alberto. Pós-Graduação lato sensu: terra de ninguém? Infocapes, Brasília, v. 7, n. 2, p. 4-18, 1999. Disponível em: <www.capes.gov.br>. Acesso em: 01 out. 2007.

HOFFMANN, Jussara. Avaliação mediadora: uma prática em construção da pré-escola à universidade. Porto Alegre: Mediação, 2003.

MORGAN, D. L. Focus groups as qualitative research. California: Sage: Thousand Oaks, 1997.

MOSCOVICI, S. Representações sociais: investigações em psicologia social. Petrópolis: Vozes, 2003.

PILATI, O. Especialização: falácia ou conhecimento aprofundado? RBPG, Brasília, v. 3, n. 5, p. 7-26, jun. 2006.

RIBEIRO, R. J. Mestrado profissional, mestrado acadêmico e doutorado. Disponível em: <www.capes.gov.br>. Acesso em: 01 out. 2007.

RISTOFF, D.; GIOLO, J. O Sinaes como sistema. RBPG, Brasília, v. 3, n. 6, p. 193-213, dez. 2006. 
SOUSA, C. P. Avaliação de Instituições de Ensino Superior: discutindo a necessidade de diretrizes metodológicas e estratégias de implantação. Estudos de Avaliação Institucional, São Paulo, v. 17, n. 35, p. 103-114, set./ dez. 2006.

SPAGNOLO, F.; SEVILLA, M. A. F. A Situação atual da pós-graduação lato sensu. Infocapes, Brasília, v. 2, n. 3, p. 7-13, jul./set. 1994. Disponível em: <www.capes.gov.br>. Acesso em: 01 out. 2007.

WESTPHAL, M. F.; BÓGUS, C. M.; FARIA, M. de M. Grupos focais: experiências precursoras em programas educativos em saúde no Brasil. Boletim da Oficina Sanitária do Panamá, v. 120, n. 6, p. 472-482, 1996.

Recebido em: janeiro 2008

Aprovado para publicação em: fevereiro 2008 
